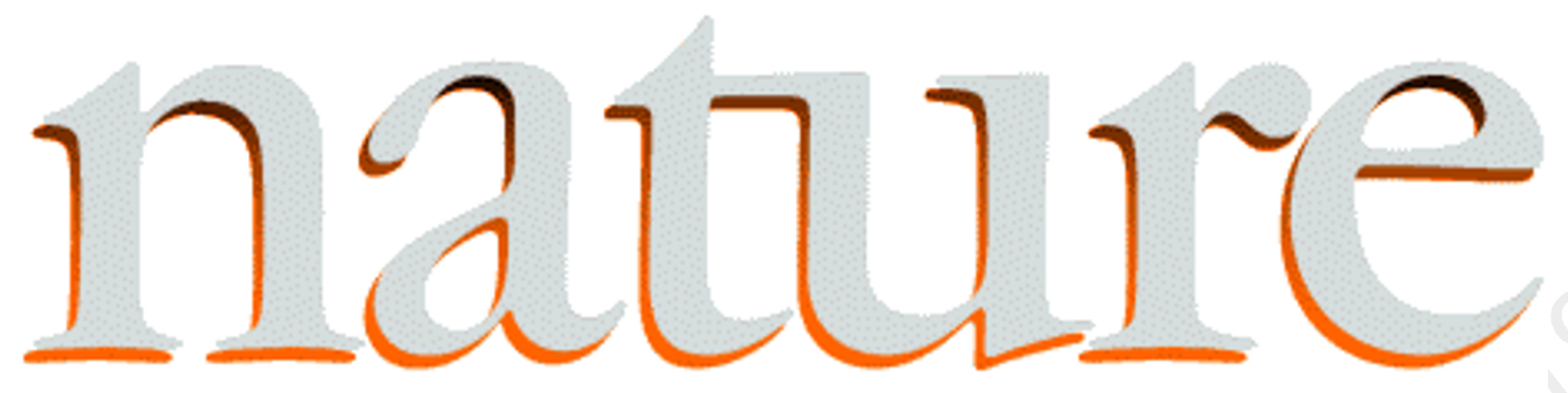

21 August 1997

letters to nature

Nature 388, 808 (1997) @ Macmillan Publishers Ltd

\title{
Correction: $\mathrm{CO}_{2}$ fixation and photoevolution of $\mathrm{H}_{2}$ and $\mathrm{O}_{2}$ in a mutant of Chlamydomonas lacking photosystem I
}

\author{
E. Greenbaum, J. W. Lee, C. V. Tevault, S. L. Blankinship \& L. J. Mets
}

Nature 376, 438-441 (1995)

We reported in this paper and elsewhere ${ }^{1}$ that mutants of the green alga Chlamydomonas reinhardtii that lacked detectable levels of functional photosystem I (PS I) are capable of photoreduction of atmospheric $\mathrm{CO}_{2}$, autotrophic growth, and sustained simultaneous photoevolution of $\mathrm{H}_{2}$ and $\mathrm{O}_{2}$. Although the absence of PS I in mutants B4 and F8 has been confirmed by physical, biochemical and genetic techniques, subsequent analyses in our own laboratories, as well as in those of colleagues to whom we have sent the mutants, indicate that there is variability in the PS I content of the cultures depending on growth conditions. Although some strains retain undetectable levels of P700, others contain variable $(0-20 \%)$ amounts of wild-type P700. (See also refs 2 , $\underline{3}$ ).

\section{References}

1. Lee, J. W., Tevault, C. V., Owens, T. G. \& Greenbaum, E. Science 273, 364-367 (1996). Links

2. Olson, J. M., Owens, T. G., Lee, J. W., Tevault, C. V. \& Greenbaum, E. Science 275, 996 (1997). Links

3. Greenbaum, E., Lee, J. W., Tevault, C. V., Blankinship, S. L. \& Mets, L. J. Nature 379, 305(1996). Links 